\title{
A MRI study of fusiform gyrus in schizotypal personality disorder
}

\section{Citation}

Dickey, Chandlee C., Robert W. McCarley, Martina M. Voglmaier, Margaret A. Niznikiewicz, Larry J. Seidman, Melissa Frumin, Sarah Toner, Susan Demeo, and Martha E. Shenton. 2003. "A MRI Study of Fusiform Gyrus in Schizotypal Personality Disorder." Schizophrenia Research 64 (1) (November): 35-39. doi:10.1016/s0920-9964(02)00529-7.

\section{Published Version}

doi:10.1016/s0920-9964(02)00529-7

\section{Permanent link}

http://nrs.harvard.edu/urn-3:HUL.InstRepos:28520542

\section{Terms of Use}

This article was downloaded from Harvard University's DASH repository, and is made available under the terms and conditions applicable to Other Posted Material, as set forth at http:// nrs.harvard.edu/urn-3:HUL.InstRepos:dash.current.terms-of-use\#LAA

\section{Share Your Story}

The Harvard community has made this article openly available.

Please share how this access benefits you. Submit a story.

\section{Accessibility}


Published in final edited form as:

Schizophr Res. 2003 November 1; 64(1): 35-39.

\title{
A MRI study of fusiform gyrus in schizotypal personality disorder
}

\author{
Chandlee C. Dickeya,b, Robert W. McCarleya, ${ }^{\text {, }}$, Martina M. VogImaiera,c, Margaret A. \\ Niznikiewicz ${ }^{a}$, Larry J. Seidman ${ }^{d}$, Melissa Frumin ${ }^{a}, b$, Sarah Tonera ${ }^{a}$, Susan Demeo ${ }^{a}$, and \\ Martha E. Shenton a, ${ }^{*}$ \\ a Clinical Neuroscience Division, Laboratory of Neuroscience, Department of Psychiatry, VA Boston \\ Healthcare System, Harvard Medical School, in collaboration with the Surgical Planning Laboratory, \\ MRI Division, Department of Radiology, Brigham and Women's Hospital, Harvard Medical School, \\ Boston, MA, USA \\ ${ }^{b}$ Departments of Neurology and Psychiatry, Brigham Behavioral Neurology Group, Brigham and \\ Women's Hospital, Harvard Medical School, Boston, MA, USA \\ c Department of Psychiatry, Cambridge Hospital, Harvard Medical School, Boston, MA, USA \\ d Department of Psychiatry, Massachusetts Mental Health Center, Harvard Medical School, Boston, \\ MA, USA
}

\begin{abstract}
The fusiform gyrus is important for face and object recognition, is abnormal in schizophrenia, but has not been studied in schizotypal personality disorder (SPD). Thin-slice MR images showed no differences, either in right, left or total fusiform gyri volumes, between subjects with SPD $(N=21)$ and normal controls $(N=19)$. However, there was a correlation between severity of illusions and magical thinking suffered by the SPD subjects and smaller right fusiform gyrus volumes. This suggests that future studies may be useful in determining the functional competence of this gyrus in SPD.
\end{abstract}

\section{Keywords}

Schizophrenia; Schizotypal personality disorder; Fusiform gyrus; Magical ideation; Illusions; MRI

\section{Introduction}

The fusiform gyrus is likely important for face and object visual processing, as demonstrated by functional magnetic resonance imaging (fMRI) (Kanwisher et al., 1997). In addition, direct electrical stimulation of the gyrus can result in the formation of complex visual illusions (Lee et al., 2000). In schizophrenia, studies show that the fusiform gyrus evinces bilateral volume reductions in both a postmortem study (McDonald et al., 2000) and in an in vivo structural MRI study (Lee et al., 2002).

Schizotypal personality disorder (SPD) shares with schizophrenia: (1) a similar genetic diathesis (Kendler et al., 1993); (2) many biologic markers (Siever et al., 2002; Siever, 1994); (3) MRI in vivo volume reductions in left temporal lobe structures (Dickey et al.,

\footnotetext{
(C) 2003 Elsevier Science B.V. All rights reserved.

* Corresponding authors. R.W. McCarley is to be contacted at VA Boston Healthcare System, Psychiatry 116A, 940 Belmont Street, Brockton, MA 02401, USA. Tel.: +1-508-583-4500x3723; fax: +1-508-586-0894. M.E. Shenton, Tel.: +1-508-583-4500x1371; fax: +1-508-586-0894. robert_mccarley@hms.harvard.edu (R.W. McCarley), martha_shenton@hms.harvard.edu (M.E. Shenton)..
} 
1999; Downhill et al., 2001); and (4) impaired recognition of facial emotions (Mikhailova et al., 1996). By definition, persons with SPD can be functionally impaired by experiencing illusions. This study was undertaken to determine whether, like schizophrenics, SPD subjects also have smaller fusiform gyrus volumes than control subjects which might help to explain the experience of illusions.

\section{Methods}

\subsection{Subject recruitment}

Subjects were recruited from the local community with the following inclusion criteria: righthanded males 18-55 years old with English as the first language; no lifetime history of neurologic disorder or ECT; no exposure to neuroleptics; no psychoactive medication usage; and no substance abuse within the last year or dependence within the last 5 years. Comparison subjects met the additional criteria of no history of Axis I disorder in self or first-degree relatives. In accordance with our local IRB committee, written informed consent was obtained from all subjects after the procedures were explained, and prior to study participation. All subjects underwent a SCID and SCID II (personality disorders) interview to determine diagnosis. For SPD subjects, responses to the SCID II section on SPD symptoms were used as scaled measures for the degree of impairment for each of the nine SPD criteria. They were group matched on age (individually matched within 3 years), parental socioeconomic status (SES), years of education, and premorbid IQ assessed by WRAT score (data available for 20 SPD, 11 control subjects). Subject overlap with two previous publications include 9/14 SPD and 11/16 comparison subjects, where previously we reported reduced left superior temporal gyrus volume and trend level reduced cortical gray matter in SPD (Dickey et al., 1999, 2000). Additionally, in another publication, the subject overlap was16/21 SPD and 12/22 comparison subjects, where we reported smaller left Heschl's gyrus volume in SPD (Dickey et al., 2000).

\subsection{MRI procedures}

Images were acquired on a 1.5-T MRI system (GE Medical Systems, Milwaukee, WI) with the same acquisition and preprocessing procedures as previously described (Dickey et al., 1999). Briefly, 1.5-mm-thick images were acquired in the coronal plane. Images were realigned to correct for head tilt and reformatted into thin $0.9375-\mathrm{mm}$ slices with isotropic voxels on which the fusiform gyrus was manually drawn (Figs. 1 and 2). The anterior boundary was one slice posterior to the complete mammillary body, and the posterior extent was the juncture of the calcarine fissure and the parieto-occipital sulcus as seen on sagittal slices previously described (Lee et al., 2002). The medial boundary was the collateral sulcus which separates the fusiform gyrus from the parahippocampus, and the lateral boundary was the sulcus separating the fusiform and inferior temporal gyri (McDonald et al., 2000).

\subsection{Statistical procedures}

On clinical measures, a Students' $t$-test was performed to compare groups. To correct for effects of head size, a linear regression procedure was performed on the left and right fusiform volumes with intracranial contents (parenchyma and CSF) as the independent variable. Saved residuals were used in subsequent analyses. All corrected data were normally distributed as per the Shapiro-Wilk test. A repeated measures ANOVA was performed with the between subject factor of diagnosis and within subject factor of hemisphere. One-way ANOVA was performed on total intracranial contents, fusiform asymmetry (right-left), and total fusiform volume (right + left). For the[C0]SPD group only, Pearson correlations were performed between ROI volumes and the scaled degree of impairment due to SPD symptoms reported during the SCID II interview. 


\section{Results}

\subsection{Clinical measures}

There was no difference between SPD and comparison subjects on age (mean SPD 37.1, NC 38.4; Students' $t=-0.41, d f=38, p=0.68$ ), years of education (mean SPD 15.0, NC 15.4; Students' $t=-1.001, d f=38, p=0.32$ ), premorbid IQ (Student's $t=-1.28, d f=29, p=0.15$ ), and parental SES (mean SPD 3.4, NC 3.9; Students' $t=-1.6, d f=37, p=0.12$ ), although there was a trend level difference in SES (mean SPD 3.35, NC 4.11; Students' $t=-1.82, d f=37$, $p=0.08)$.

\subsection{Structural measures}

There was no difference in whole brain volumes between the two groups (one-way ANOVA $F=0.45, d f=1, p=0.51)$. Repeated measures ANOVA revealed no main effect for fusiform side $(F=0.016, d f=1, p=0.9)$, nor diagnosis by side $(F=0.036, d f=1, p=0.85)$ with an effect size of 0.001 (very small) (Fig. 3). Nor was there a difference between groups in fusiform asymmetry (one-way ANOVA $F=0.036, d f=1, p=0.85$ ) or total fusiform volume (one-way ANOVA $F=0.007, d f=1, p=0.93$ ). The interrater reliability for the manual drawing of the fusiform for six cases by three raters was high (intraclass correlation $r=0.9935$ (right) and $r$ $=0.9988($ left $)$ ).

\subsection{Clinical structural correlations}

A negative correlation was found between the volume of the right fusiform gyrus and degree of impairment by self-report from illusions (Pearson $r=-0.48, N=21, p<0.03$ ) and magical thinking (Pearson $r=-0.55, N=21, p=0.01$ ).

\section{Discussion}

The main news of this report is that, unlike what is seen in schizophrenia, there appears to be no difference in MRI fusiform gyrus volumes in SPD subjects compared with normal comparison subjects. The small effect size (0.001) suggests that simply increasing the subject number will not affect this result.

However, these findings are interesting as they demonstrate that only selective regions within the temporal lobe seem to be affected in SPD morphometrically (Dickey et al., 2002a) and functionally (Buchsbaum et al., 2002), although more diffuse abnormalities are seen in schizophrenia (McCarley et al., 1999; Shenton et al., 2001; Siever et al., 2002). For example, brain abnormalities in SPD have been demonstrated in the left superior temporal gyrus (Dickey et al., 1999; Downhill et al., 2001), specifically Heschl's gyrus (Dickey et al., 2002b), and whole temporal lobe (Downhill et al., 2001), but not in medial temporal lobe structures specifically (Dickey et al., 1999), whereas medial temporal lobe structures (Barta et al., 1990; Buchanan et al., 1993; Shenton et al., 1992) and fusiform gyrus (Lee et al., 2002) have been implicated in schizophrenia. It is conjecture, but perhaps more language-oriented areas of the temporal lobe (left superior temporal gyrus and Heschl's gyrus) are affected in SPD (Dickey et al., 2002b), whereas areas more involved in emotional processing (amygdala: Whalen et al., 1998; and fusiform gyrus: Lang et al., 1998) are spared in SPD.

Whether other areas of visual processing, specifically striate and extrastriate cortex, are implicated in SPD remains unknown. Thalamic abnormalities have been reported in SPD (Hazlett et al., 1999), but the lateral geniculate nucleus, which is involved in transmission of visual information, has not been separately examined. 
Several limitations to this study may attenuate the findings. First, this study does not examine females with SPD. Both male and female schizophrenic subjects postmortem exhibit an abnormality of the fusi-form gyrus (McDonald et al., 2000), and perhaps inclusion of female SPD subjects would have altered the results. Second, the recruitment strategy selected only for subjects who have not been treated pharmacologically for SPD, and this narrow subject group may effect the generalizability of the finding. Finally, this study examined volume only, and it may be that there are differences in the shape of the fusiform, as others have demonstrated differences in the shape of other brain regions in SPD (Downhill et al., 2000).

There is a correlation between degree of impairment from magical thinking and illusions with smaller right fusiform gyrus volumes in SPD subjects. The relationship between magical ideation and the fusiform gyrus is not clear, in part as magical ideation specifically has been infrequently studied. Speculatively, however, magical ideation may engage visual imagery. Indeed, half of our subjects reported "seeing" images when asked questions from the SCID II designed to probe for magical ideation. Generating mental images does involve fusiform activation (D'Esposito et al., 1997). The correlation between illusions and smaller fusiform volume is more clear as direct electrical stimulation of the fusiform gyrus in epilepsy patients produces complex visual illusions such as faces, animals, panoramas, images from memory, and metamorphopsia (Lee et al., 2000), not unlike what is described by the SPD subjects in this study. Future functional imaging studies of fusiform activity may be important to more fully understand the role of this gyrus in schizophrenia spectrum disorders.

\section{Acknowledgments}

This research was supported by NIMH MH 52807 (R.W.M.); NIMH MH 40799 (R.W.M.); NIMH MH 01110 (M.E.S.); NIMH MH 50740 (M.E.S.); and Department of Veterans Affairs Center for Clinical and Basic Neuroscience Studies of Schizophrenia (R.W.M.); VA Merit Awards (R.W.M. and M.E.S.); VA Career Development Award (C.C.D.); and VA Psychiatry Research/Neuroscience Fellowship (M.F.).

We wish to thank Marie Fairbanks for her administrative support and Anita Madan for her support in the production of this project.

\section{References}

Barta PE, Pearlson GD, Powers RE, Richards SS, Tune LE. Auditory hallucinations and smaller superior temporal gyral volume in schizophrenia. Am. J. Psychiatry 1990;147:1457-1462. [PubMed: 2221156]

Buchanan RW, Breier A, Kirkpatrick B, et al. Structural abnormalities in deficit and nondeficit schizophrenia [see comments]. Am. J. Psychiatry 1993;150:59-65. [PubMed: 8417581]

Buchsbaum M, Nenadic I, Hazlett E, et al. Differential metabolic rates in prefrontal and temporal Brodman areas in schizophrenia and schizotypal personality disorder. Schizophr. Res 2002;54:141150. [PubMed: 11853988]

D'Esposito M, Detre J, Aguirre G, et al. A functional MRI study of mental image generation. Neuropsychologia 1997;35:725-730. [PubMed: 9153035]

Dickey CC, McCarley RW, Voglmaier MM, et al. Schizotypal personality disorder and MRI abnormalities of temporal lobe gray matter. Biol. Psychiatry 1999;45:1393-1402. [PubMed: 10356620]

Dickey CC, Shenton M, Hirayasu Y, et al. Large CSF volume not attributable to ventricular volume in schizotypal personality disorder. Am. J. Psychiatry 2000;157:48-54. [PubMed: 10618012]

Dickey C, McCarley R, Shenton M. The brain in schizotypal personality disorder: a review of the structural MRI and CT findings. Harv. Rev. Psychiatr. 2002a in press.

Dickey C, McCarley R, Voglmaier M, et al. Smaller left Heschl's gyrus volume in patients with schizotypal personality disorder. Am. J. Psychiatry 2002b;159:1521-1527. [PubMed: 12202272]

Downhill J, Buchsbaum M, Wei T, et al. Shape and size of the corpus callosum in schizophrenia and schizotypal personality disorder. Schizophr. Res 2000;42:193-208. [PubMed: 10785578] 
Downhill J, Buchsbaum M, Hazlett E, et al. Temporal lobe volume determined by magnetic resonance imaging in schizotypal personality disorder and schizophrenia. Schizophr. Res 2001;48:187-199. [PubMed: 11295372]

Hazlett EA, Buchsbaum MS, Byne W, et al. Three-dimensional analysis with MRI and PET of the size, shape, and function of the thalamus in the schizophrenia spectrum. Am. J. Psychiatry 1999;156:11901199. [PubMed: 10450259]

Kanwisher N, McDermott J, Chun MN. The fusiform face area: a module in human extrastriate cortex specialized for face perception. J. Neurosci 1997;17(11):4302-4311. [PubMed: 9151747]

Kendler KS, McGuire M, Gruenberg AM, O'Hare A, Spellman M, Walsh D. The Roscommon family study I. Methods, diagnosis of probands, and risk of schizophrenia in relatives. Arch. Gen. Psychiatry 1993;50:527-540. [PubMed: 8317947]

Lang PJ, Bradley MM, Fitzsimmons JR, et al. Emotional arousal and activation of the visual cortex: an fMRI analysis. Psychophysiology 1998;35:199-210. [PubMed: 9529946]

Lee H, Hong S, Seo D, Tae W, Hong S. Mapping of functional organization in human visual cortex. Electrical cortical stimulation. Neurology 2000;54:849-854. [PubMed: 10690975]

Lee C, McCarley R, Salisbury D, et al. Fusiform gyrus volume reduction in first episode schizophrenia: a MRI study. Arch. Gen. Psychiatry. 2002 in press.

McCarley RW, Wible CG, Frumin M, et al. MRI anatomy of schizophrenia. Biol. Psychiatry 1999;45:1099-1119. [PubMed: 10331102]

McDonald B, Highley J, Walker M, et al. Anomalous asymmetry of fusiform and parahippocampal gyrus gray matter in schizophrenia: a postmortem study. Am. J. Psychiatry 2000;157:40-47. [PubMed: 10618011]

Mikhailova E, Vladimirova T, Iznak A, Tsusulkovskaya E, Sushko N. Abnormal recognition of facial expression of emotions in depressed patients with major depression disorder and schizotypal personality disorder. Biol. Psychiatry 1996;40:697-705. [PubMed: 8894061]

Shenton ME, Kikinis R, Jolesz FA, et al. Abnormalities of the left temporal lobe and thought disorder in schizophrenia. A quantitative magnetic resonance imaging study. N. Engl. J. Med 1992;327:604612. [PubMed: 1640954]

Shenton M, Dickey C, Frumin M, McCarley R. A review of MRI findings in schizophrenia. Schizophr. Res 2001;49:1-52. [PubMed: 11343862]

Siever LJ. Biologic factors in schizotypal personal disorders. Acta Psychiatr. Scand., Suppl 1994;384:4550. [PubMed: 7879643]

Siever L, Koeningsberg H, Harvey P, et al. Cognitive and brain function in schizotypal personality disorder. Schizophr. Res 2002;54:157-167. [PubMed: 11853990]

Whalen P, Rauch S, Etcoff N, McInerney S, Lee M, Jenike M. Masked presentations of emotional facial expressions modulate amygdala activity without explicit knowledge. J. Neurosci 1998;18:411-418. [PubMed: 9412517] 


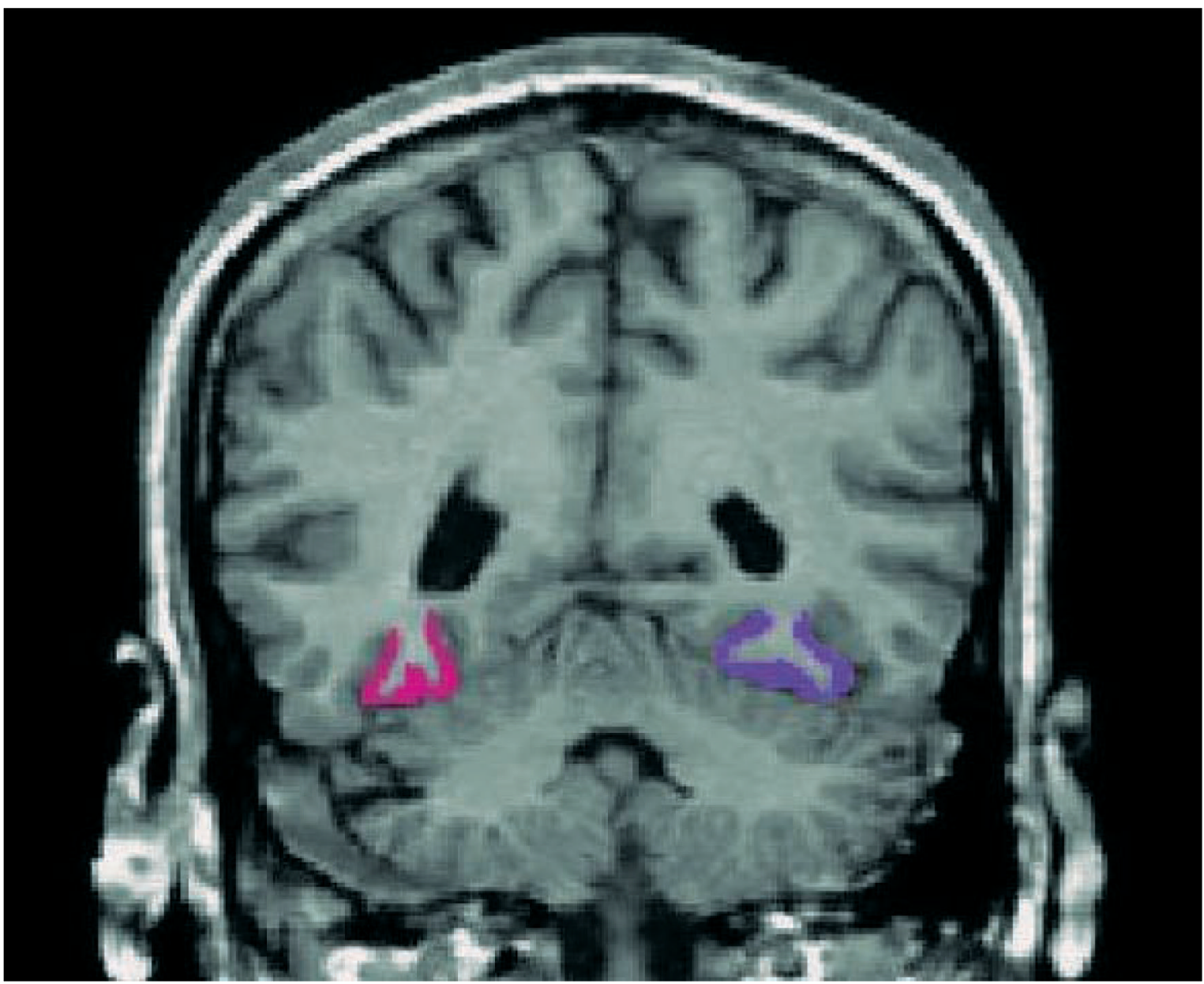

Fig. 1.

Manual tracing of right (pink) and left (purple) fusiform gyrus on a coronal image of SPD subject. 


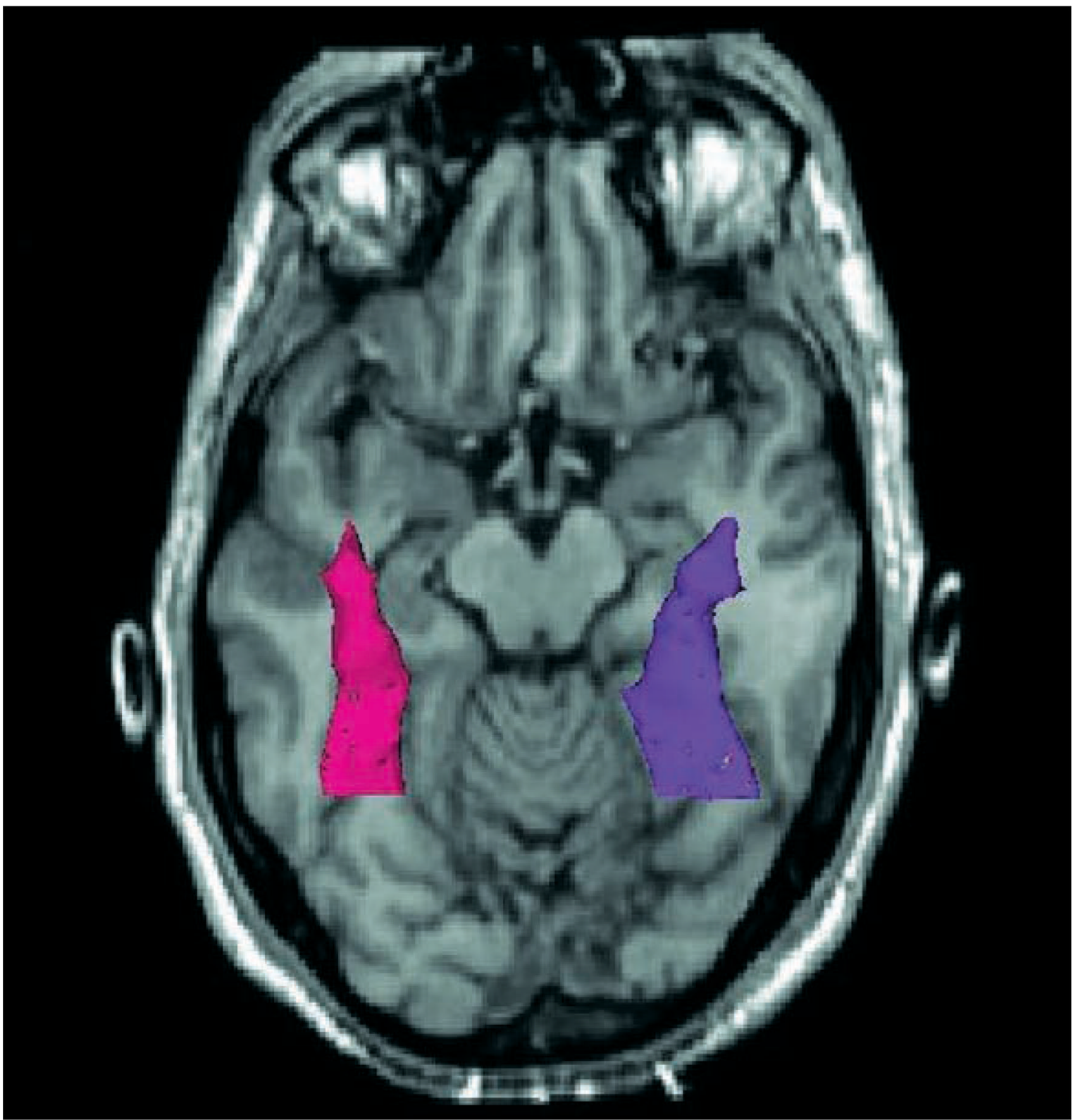

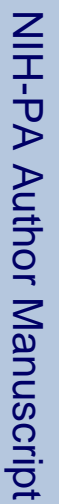

Fig. 2.

Three-dimensional model of the fusiform in (1) superimposed on an axial slice. 

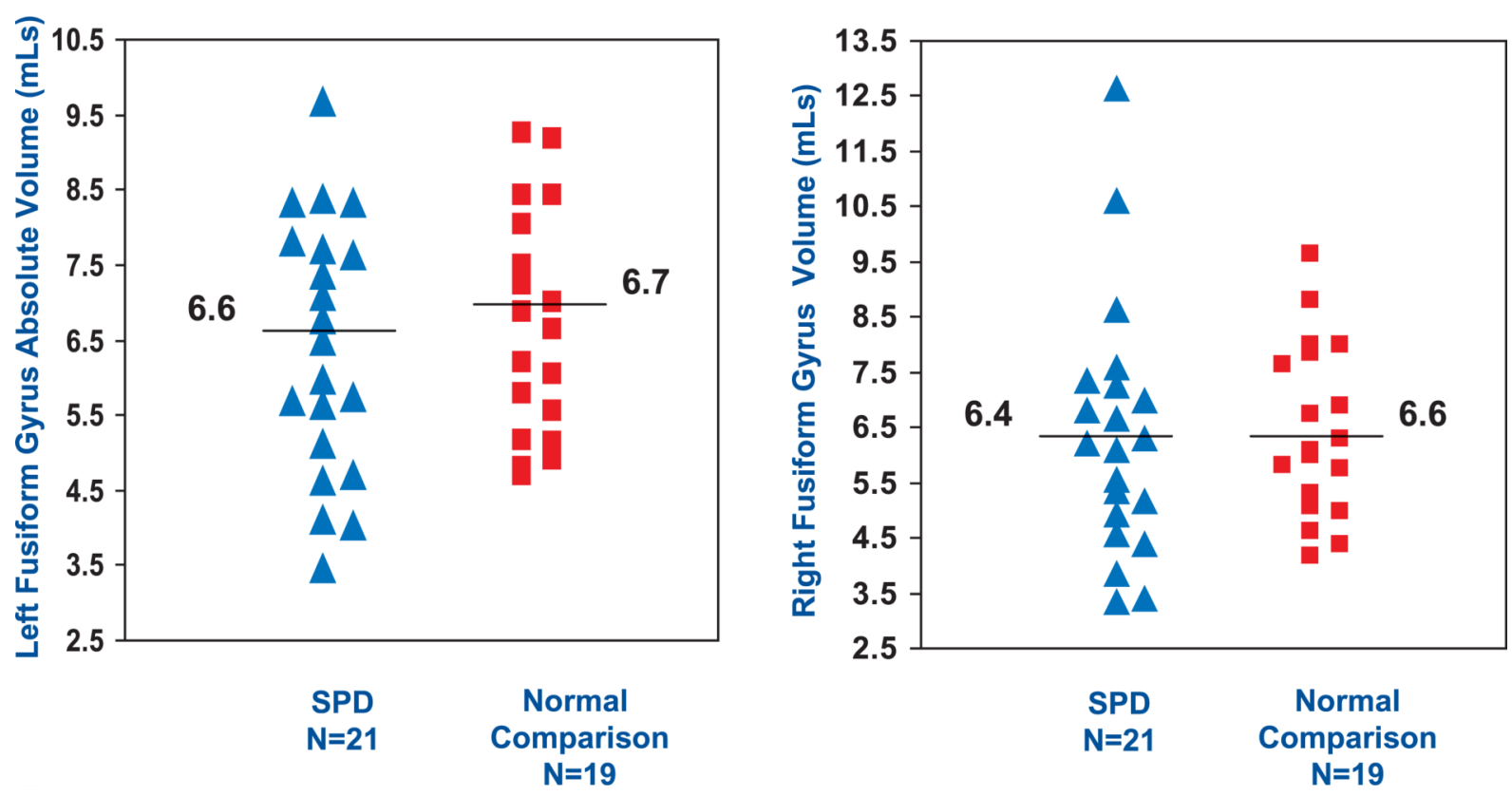

Fig. 3.

Scatterplot of SPD and comparison subjects' absolute right and left fusiform volumes in $\mathrm{ml}$ with mean volumes indicated (note that this figure demonstrates absolute volumes not corrected for intracranial contents, but statistics were performed on corrected and normally distributed data). 